\title{
Simulation of SEVIRI infrared channels: a case study from the Eyjafjallajökull April/May 2010 eruption
}

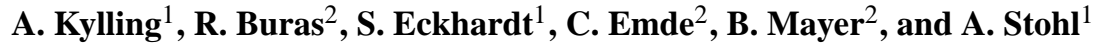 \\ ${ }^{1}$ NILU - Norwegian Institute for Air Research, P.O. Box 100, 2027 Kjeller, Norway \\ ${ }^{2}$ Meteorological Institute, Ludwig Maximilian University, Munich, Germany
}

Correspondence to: A. Kylling (arve.kylling@nilu.no)

Received: 26 September 2012 - Published in Atmos. Meas. Tech. Discuss.: 23 October 2012

Revised: 27 February 2013 - Accepted: 28 February 2013 - Published: 13 March 2013

\begin{abstract}
Infrared satellite images are widely and successfully used to detect and follow atmospheric ash from erupting volcanoes. We describe a new radiative transfer model framework for the simulation of infrared radiances, which can be compared directly with satellite images. This can be helpful to get insight into the processes that affect the satellite retrievals. As input to the radiative transfer model, the distribution of ash is provided by simulations with the FLEXPART Lagrangian particle dispersion model, meteorological cloud information is adopted from the ECMWF analysis and the radiative transfer modelling is performed with the MYSTIC 3 -D radiative transfer model. The model framework is used to study an episode during the Eyjafjallajökull eruption in 2010. It is found that to detect ash by the reverse absorption retrieval technique, accurate representation of the ash particle size distribution is required. Detailed investigation of individual pixels displays the radiative effects of various combinations of ash, liquid water and ice clouds. In order to be clearly detectable, the ash clouds need to be located at some distance above other clouds. If ash clouds are mixed with water clouds or are located only slightly above water clouds, detection of the ash becomes difficult. Simulations were also made using the so-called independent pixel approximation (IPA) instead of the fully 3-D radiative transfer modelling. In the two simulations, different clouds (or different parts of the clouds) or the ground are effectively emitting radiation towards the instrument, thus causing differences in the brightness temperature of up to $\pm 25 \mathrm{~K}$. The presented model framework is useful for further studies of the processes that affect satellite imagery and may be used to test both new and existing ash retrieval algorithms.
\end{abstract}

\section{Introduction}

The Eyjafjallajökull eruption in April/May 2010 is very well documented through numerous ground-based, air-borne and satellite observations and modelling studies (see for example Gudmundsson et al., 2012 and special issues of Atmospheric Chemistry and Physics, Hasager et al., 2010, and Journal of Geophysical Research-Atmospheres JGR Special Section, 2011-2012). As such the eruption has provided a unique wealth of information on which further investigations of the eruption may build.

Satellite measurements are indispensable for monitoring the spatial and temporal evolution of volcanic ash clouds. During the Eyjafjallajökull eruption, the infrared (IR) channels of the Spinning Enhanced Visible and Infrared Imager (SEVIRI) on board the Meteosat Second Generation (MSG, Meteosat-9) geostationary satellite provided day and night coverage with high temporal $(15 \mathrm{~min})$ and spatial resolution $\left(3 \times 3 \mathrm{~km}^{2}\right.$ at sub-satellite point to about $10 \times 10 \mathrm{~km}^{2}$ at the edges of the scan). The SEVIRI retrieval of ash concentration is based on the inverse absorption technique to provide ash loading and effective particle radius (Prata, 1989; Prata and Grant, 2001; Wen and Rose, 1994). A description of the methodology, results and validation for the Eyjafjallajökull eruption is given by Prata and Prata (2012). Dispersion models can describe the motion of the ash particles. They were actively used by the London Volcanic Ash Advisory Center (VAAC) during the Eyjafjallajökull eruption as a basis for provision of advisories to the aviation industry. The dispersion of ash depends critically on the total erupted mass and the altitude to which it is effectively emitted as well as the variation of ash emission rate with time. 
However, neither the total erupted mass nor its altitude are readily available. Stohl et al. (2011) determined time- and height-resolved volcanic emissions for the Eyjafjallajökull eruption. They coupled a priori source estimates and the output of the FLEXPART Lagrangian particle dispersion model (Stohl et al., 2005) with SEVIRI derived ash column concentrations through an inversion scheme (Eckhardt et al., 2008) to get an improved a posteriori estimate of the ash emission source. The a posteriori ash emission based dispersion model results improved the agreement with independent groundbased, air-borne and space-based observations (Stohl et al., 2011; Kristiansen et al., 2012).

Simulation of the SEVIRI IR images can provide new insight into the processes controlling the measured satellite radiances and may help to improve the ash retrieval. Millington et al. (2012) simulated SEVIRI infrared channels with the Radiative Transfer for TOVS (RTTOV) radiative transfer model (Saunders et al., 1999) to produce ash images to aid ash concentration forecasts. In their study, the Numerical Atmospheric dispersion Modelling Environment (NAME, Jones et al., 2007) was used to describe the ash cloud, and meteorological clouds were taken from the UK Met Office's Numerical Weather Prediction. We describe a new model framework combining ash clouds from FLEXPART and meteorological clouds from European Centre for Medium-Range Weather Forecasts (ECMWF) analysis to provide input to the fully three-dimensional (3-D) Monte Carlo code for the physically correct tracing of photons in cloudy atmospheres (MYSTIC) radiative transfer model (Mayer, 2009), which is used to simulate brightness temperatures corresponding to the 10.8 and $12.0 \mu \mathrm{m}$ channels of the SEVIRI instrument.

The aim of the present paper is to describe this fully 3-D modelling tool for the simulation of SEVIRI infrared images. After presenting the various components of the modelling framework, a representative case from the Eyjafjallajökull eruption is studied in detail to demonstrate the usage of the model to investigate the various processes affecting the satellite images, including 3-D radiative transfer effects.

\section{Ash transport model}

We used the Lagrangian particle dispersion model FLEXPART (Stohl et al., 1998, 2005) to simulate the dispersion of volcanic ash. The ash emission rates as a function of time and height used for the simulations were determined in a previous study using inverse modelling that coupled a priori source information and FLEXPART model data with SEVIRI ash retrievals (Stohl et al., 2011). Using this source term, FLEXPART was run in forward mode and was driven with meteorological data from the ECMWF analyses with $0.18 \times 0.18^{\circ}$ horizontal resolution and 91 vertical model levels. The ash particle size distribution included 25 particle size classes with radii in the range $0.125-125 \mu \mathrm{m}$. The simulation accounted for gravitational particle settling as well as dry and wet deposition, but no ash aggregation processes were accounted for. Formation of sulphate particles $\left(\mathrm{H}_{2} \mathrm{SO}_{4}\right)$ was also not simulated. The model output had a horizontal spatial resolution of $0.25 \times 0.25^{\circ}$ and a vertical resolution of $250 \mathrm{~m}$.

\section{Radiative transfer model}

The MYSTIC 3-D radiative transfer model has been described in a series of publications (Mayer et al., 2010; Emde et al., 2010; Buras and Mayer, 2011) and has been extensively validated in the Intercomparison of 3-D radiation codes (Cahalan et al., 2005). It is run within the libRadtran model framework (Mayer and Kylling, 2005) and can be driven with 3-D ash, ice and water cloud fields. MYSTIC also includes the option to simulate images. This feature is utilised to simulate SEVIRI brightness temperature images for the $10.8 \mu \mathrm{m}$ and $12.0 \mu \mathrm{m}$ channels which are used for operational retrievals of ash column loadings (Prata, 1989; Prata and Prata, 2012). If not otherwise stated, 4000 photons were simulated for each pixel, giving a standard deviation in the simulated brightness temperature of less than $0.25 \mathrm{~K}$ for more than $94 \%$ of the pixels. The computing time of MYSTIC depends on the number of scattering events taking place. With the setup presented here the computing time for a single scene is on the order of two hours on a 10 node cluster. As such the presented model framework is not applicable for operational use in its present configuration.

\subsection{Volcanic cloud}

For the Eyjafjallajökull episode, FLEXPART 3-D fields of ash particle concentration for 25 different size classes with radii between $0.125-125 \mu \mathrm{m}$ were available. Figure 1 shows the total column density for particle radii between 0.125 and $25.0 \mu \mathrm{m}$. The 253 -D ash particle fields were ingested into the MYSTIC radiative transfer model. The ash particles were assumed to be spherical and made of andesite (Stohl et al., 2011; Millington et al., 2012). The refractive index of andesite was taken from Pollack et al. (1973) and are the same as used in the SEVIRI retrieval (Fig. 2). Optical properties were obtained from Mie calculations which were made for each particle radius. It is noted that the present approach avoids the need to assume any specific fixed aerosol size distribution, but rather takes the size distributions in every voxel directly from FLEXPART, thus allowing more realistic simulations. The implications of this improvement are discussed below.

Sulphur dioxide was also emitted by the Eyjafjallajökull volcano (see e.g. Thomas and Prata, 2011). As the sulphur dioxide absorption cross section is negligible for the $10.8 \mu \mathrm{m}$ and $12.0 \mu \mathrm{m}$ channels it is not included in the present simulations. For most of the eruption, satellite data indicate that the ash and sulphur dioxide were collocated according 

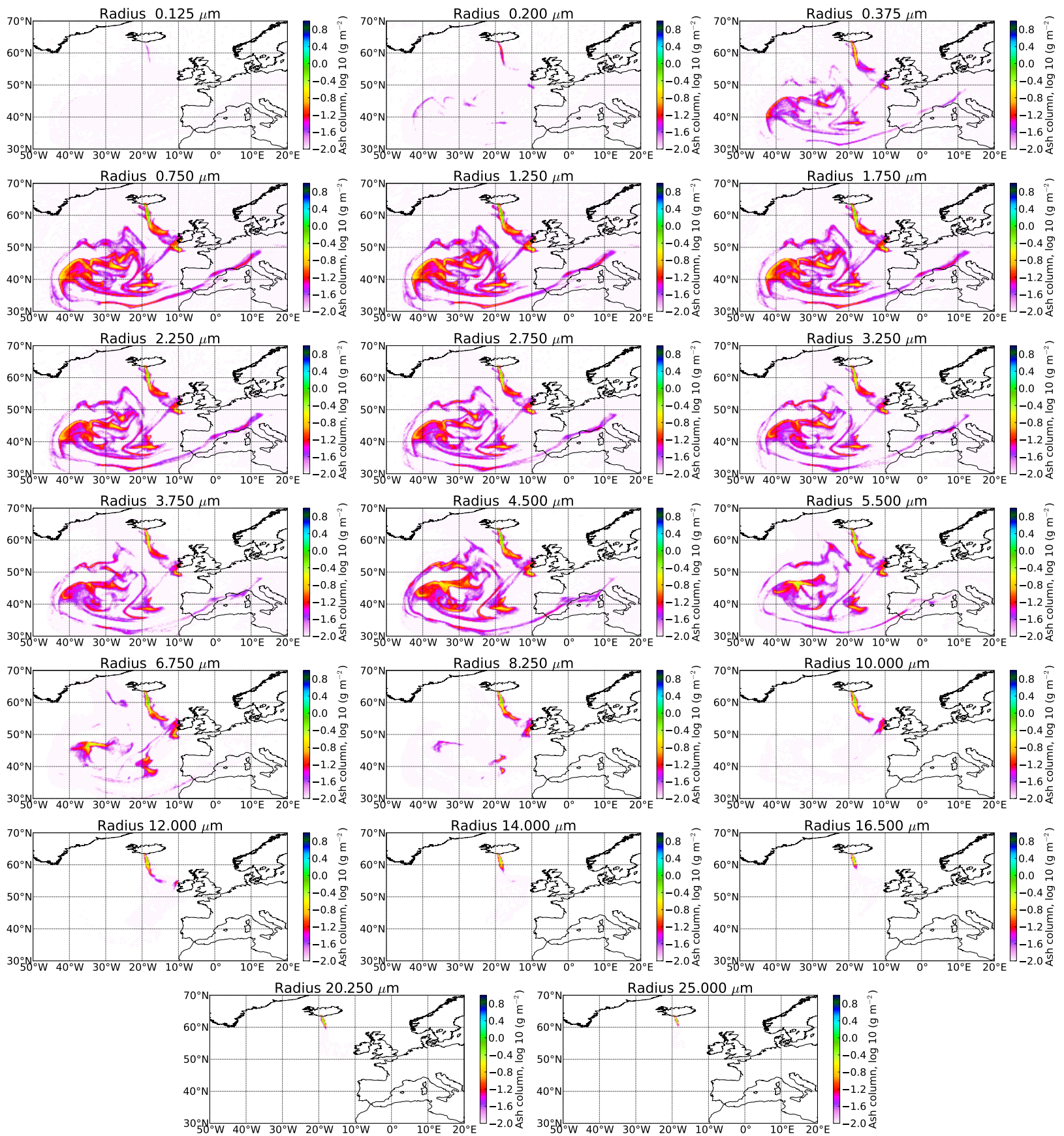

Fig. 1. The total column density of the ash for various particle radii as simulated by the FLEXPART Langrangian particle dispersion model for 11 May 2010 at 12:00 UTC.

to Thomas and Prata (2011). Sulphur dioxide may be converted to sulphate aerosols. Similar to volcanic ash, sulphate aerosols are detectable by the inverse absorption technique (Prata, 1989). Sulphate aerosols are not included in the simulations, their radiative effect may, however, be present in the measurements.

\subsection{Liquid water and ice clouds}

Liquid water clouds were obtained from global ECMWF analyses with $0.25^{\circ} \times 0.25^{\circ}$ horizontal resolution and 91 vertical model levels. The 2-D ECMWF liquid water field for the level closest to the FLEXPART output layer was interpolated to the FLEXPART output resolution. The effective radius, $r_{\text {eff }}$, of the water droplets was calculated using the 


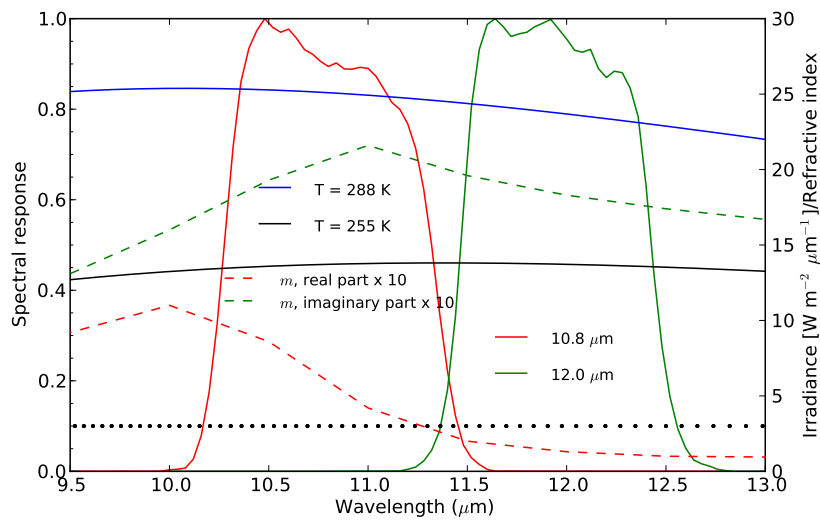

Fig. 2. The spectral responses for the 10.8 (red line) and $12.0 \mu \mathrm{m}$ (green line) channels of the SEVIRI instrument. The Planck distribution for two temperatures is shown in black and blue. The real and imaginary part of the refractive index $m$ of andesite from Pollack et al. (1973) are showed in red and green dashed lines, respectively. The dotted black line illustrates the wavelength grid of the LOWTRAN parameterization (Pierluissi and Peng, 1985; Ricchiazzi et al., 1998).

parameterization of Martin et al. (1994). The optical properties of the water clouds were calculated from Mie theory.

Ice clouds were extracted from the same ECMWF analyses as for the water clouds. The ice particles were assumed to consist of solid columns with $r_{\text {eff }}$ calculated from the parameterization of Wyser (1998) and McFarquhar et al. (2003). The optical properties were taken from Yang et al. (2005) and processed as described by Key et al. (2002).

The liquid (Martin et al., 1994) and ice (Wyser, 1998; McFarquhar et al., 2003) water cloud effective radii parameterizations have earlier been used by Bugliaro et al. (2011) to simulate SEVIRI radiances.

\subsection{Temperature, surface emissivity and elevation data}

The 3-D temperature distribution was extracted from the ECMWF analyses. For the surface temperature, the $2 \mathrm{~m}$ temperature from ECMWF was used. For IR radiative transfer simulations the temperature enters the problem in the Planck function (primary effect) and in temperature dependent absorption and scattering cross sections (secondary effect). In the MYSTIC model simulations, the 3-D temperature field was used to provide 3-D distribution of the emission by the Planck function. The present implementation of MYSTIC does not allow 3-D temperature dependence in absorption and scattering cross sections. Thus, a horizontally constant temperature had to be used for the calculation of the temperature-dependent absorption and scattering cross sections. These temperatures were taken from the sub-arctic summer atmosphere Anderson et al. (1986). Similarily, the horizontal variation in the water vapour cannot be accounted for in the present version of MYSTIC. Thus the water vapour profile from the sub-arctic summer atmosphere of (Anderson et al., 1986) was adopted for the whole domain. To estimate the effect of a fixed water vapour profile, 1-D simulations were made for each pixel with the DISORT radiation code (Stamnes et al., 1988; Buras et al., 2011). Simulations with the fixed water vapour profile and one with water vapour from the ECMWF were compared. Differences in brightness temperatures in the range -1.1 and $0.9 \mathrm{~K}$ were found between the two simulations. The fixed water vapour profile on average increased the $10.8-12.0 \mu \mathrm{m}$ brightness temperature difference by $0.07 \mathrm{~K}$ for pixels identified as ash. Thus, for the example investigated below, about $8 \%$ of ash affected pixels may miss detection by assuming a fixed water vapour profile. Surface emissivity values for the SEVIRI channels were taken from Borbas and Ruston (2010). Elevation data were taken from the Global 30 Arc Second Elevation data set (GTOPO30, available from http://eros.usgs.gov).

\subsection{Spectral resolution}

To simulate the signal obtained in a SEVIRI channel, the radiance should first be calculated for a number of wavelengths and the results convolved with the spectral response function for the channel. The accuracy of the result will depend on the spectral resolution of the simulation. The spectral responses for the 10.8 and $12.0 \mu \mathrm{m}$ channels of the SEVIRI instrument are shown in Fig. 2. One-dimensional simulations of the top of the atmosphere brightness temperature were made for the spectral range covered by the $10.8 \mu \mathrm{m}$ and $12.0 \mu \mathrm{m}$ SEVIRI channels for various spectral resolutions. For the gas absorption, the LOWTRAN parameterization was used (Pierluissi and Peng, 1985; Ricchiazzi et al., 1998). Water and andesite ash clouds of varying density were included in the simulations. The spectral resolution of the optical properties of the andesite taken from Pollack et al. (1973) is about $0.05 \mu \mathrm{m}$. The ash optical properties vary relatively smoothly over the wavelength region discussed here (dashed lines, Fig. 2). Simulations were made with $0.01,0.1$ and $0.2 \mu \mathrm{m}$ resolution. In addition simulations were made with the varying LOWTRAN spectral resolution (see dotted black lines in Fig. 2). Simulations for all spectral resolutions clearly discriminate between the water and the ash cloud. The spectral resolution, $0.2 \mu \mathrm{m}$, that used the least amount of computer time, is used in all subsequent simulations.

\section{SEVIRI and volcanic ash}

The SEVIRI instrument has 12 channels from the visible to the infrared. It views the Earth disk with a total field of view of $70^{\circ}$ from a geostationary location at $0^{\circ} \mathrm{E}$. The 10.8 and $12.0 \mu \mathrm{m}$ infrared channels may be used to discriminate pixels with volcanic ash from pixels with ice and/or water clouds. The brightness temperature difference, $\mathrm{BTD}=\mathrm{BT}(10.8)-$ $\mathrm{BT}(12.0)$, is negative for volcanic clouds and positive for 
ice and water clouds due to the different spectral behaviour of the respective refractive indices. Once a pixel with ash has been identified, the total column airborne ash loadings and particle size may be retrieved (Prata, 1989; Grant and Heisler, 2001; Wen and Rose, 1994). The strength of the ash signal in the BTD does not correlate perfectly with the ash column loadings as the ash signal depends also on a number of other factors such as ash particle size, ash mineral composition, ash height, temperature contrast of ash cloud and surface, water vapour, presence of ice and water clouds and viewing angle. Below we utilise the new model framework to investigate the sensitivity of the ash signal to changes in the values of some of these parameters for a case during the Eyjafjallajökull eruption.

\section{Case study}

After a quiet period following the initial eruption phase 1418 April, the Eyjafjallajökull eruption increased in strength on 5 May and continued to emit ash into the atmosphere until 19 May (Gudmundsson et al., 2012). We chose to investigate a case where both aged ash transported far away from the volcano as well as fresh ash close to the volcano were present in the atmosphere, namely 11 May. The situation on 11 May 2010 at noon just south of Iceland is presented in Fig. 3 as recorded by the Moderate Resolution Imaging Spectroradiometer (MODIS) instrument. The SEVIRI $10.8 \mu \mathrm{m}$ channel brightness temperature recorded $15 \mathrm{~min}$ before the MODIS image is shown in the left panel of Fig. 4. The volcanic plume is readily identified in both images. Also note similarities in the meteorological cloud structures both to the east and west of the plume in both images.

\subsection{Simulated versus measured ash patterns}

The individual total column densities of the ash, ice and water cloud fields as input to the MYSTIC radiative transfer model are shown in the left column of Fig. 5. The MYSTIC simulation of the $10.8 \mu \mathrm{m}$ channel including ECMWF ice and liquid water clouds and the FLEXPART ash cloud is shown in the right panel of Fig. 4. Qualitatively the simulation reproduces the main features of the observation, including the ash plume signal south of Iceland. For example, Iceland and the ocean to the south was partly cloud-free (Fig. 3), thus allowing the near-vent ash to be readily identified in both the simulation and the measurement. The high altitude mixed ice and liquid water cloud to the west of Iceland give low brightness temperatures as do the high altitude ice clouds present over the Alps and northern France and Belgium and west of northern Norway. These high-altitude clouds are well represented by the model simulations. There are no ice clouds in the Atlantic between about $10-45^{\circ} \mathrm{W}$ and $35-50^{\circ} \mathrm{N}$. However, a number of differences between the measurement and the simulation are also evident. The horizontal resolution

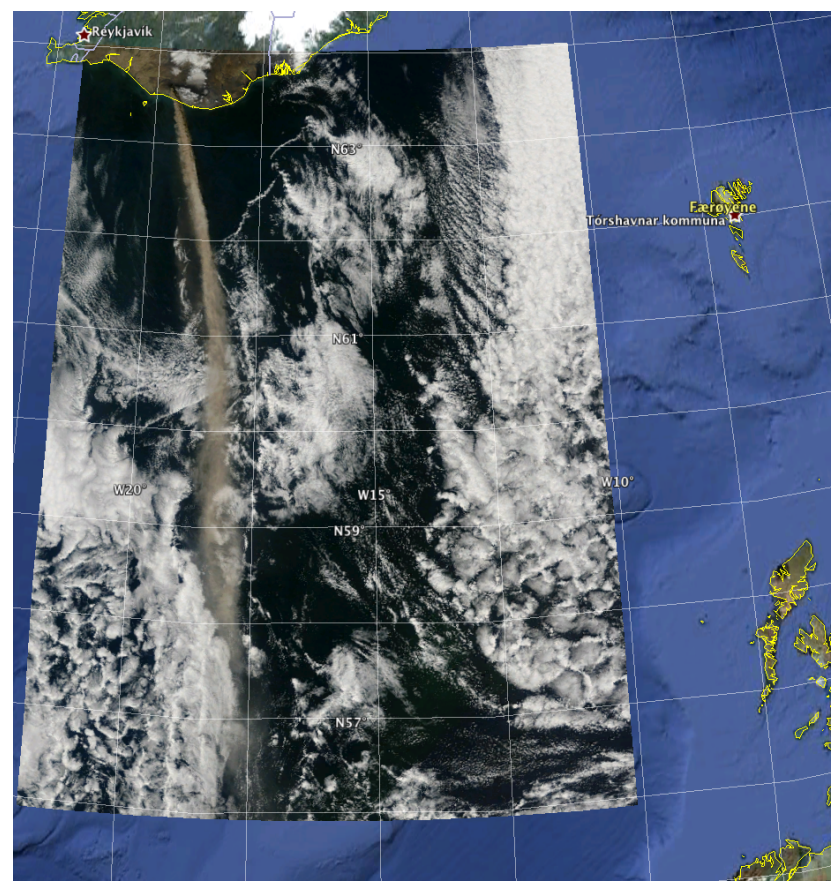

Fig. 3. MODIS true colour image of the Eyjafjallajökull eruption on the 11 May 2010 at 12:15 UTC.

of the FLEXPART simulations is $0.25 \times 0.25^{\circ}$ which corresponds to about 28 and $16 \mathrm{~km}$ in the latitude and longitude directions, respectively. The spatial resolution of the SEVIRI images varies from $3 \times 3$ to $10 \times 10 \mathrm{~km}^{2}$ (Fig. 1, Prata and Prata, 2012). As such the measurement shows more spatial structure than the model simulation. Also the liquid and ice water cloud fields from ECMWF available every $6 \mathrm{~h}$, lack the fine spatial structures due to the limitations of models used. This is clearly evident in the clouds east and west of the plume as seen in Figs. 3 and 4. With the exception of the eastern cloud close to the Icelandic coast, these clouds are not present in the ECMWF cloud fields (Fig. 5). The eastern cloud, however, appears to be at a too low altitude as it produces warmer brightness temperatures than those measured, compare left and right panels of Fig. 4. In the Atlantic the simulations miss the smaller scale structures. Furthermore, the simulations are too warm just east of Iceland and over Northern Scandinavia. These differences between the measured and simulated images are due to the spatial resolution of the ice and liquid water clouds; errors in the ECMWF cloud altitude; the lack of cloud; or presence of cloud where none should be. Inaccuracies in the input data fields to the radiative transfer model may have an impact on the reliability of the simulated images when these are used in an ash situation. However, for sensitivity studies the precise location of the clouds may be of less importance.

The presence of ash reduces the $10.8-12.0 \mu \mathrm{m}$ brightness temperature differences. As noted above, pixels containing ash are identifed by negative $10.8-12.0 \mu \mathrm{m}$ brightness 

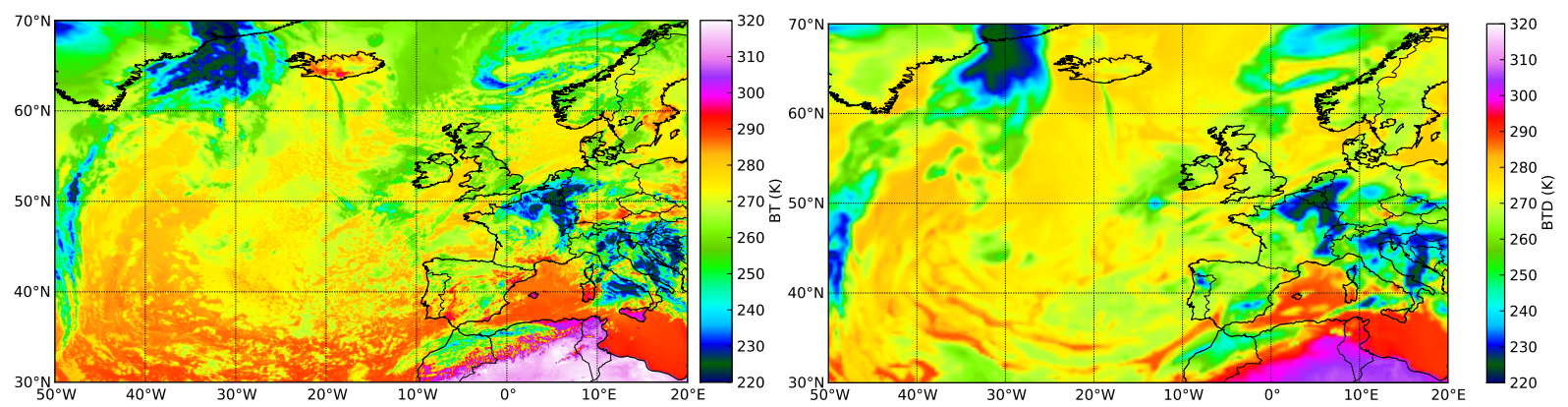

Fig. 4. Left panel: brightness temperatures as measured by the $10.8 \mu \mathrm{m}$ channel of the SEVIRI instrument. Right panel: the $10.8 \mu \mathrm{m}$ brightness temperature as simulated by the MYSTIC radiative transfer model. The simulation includes ECMWF ice and water cloud in addition to the FLEXPART ash cloud.
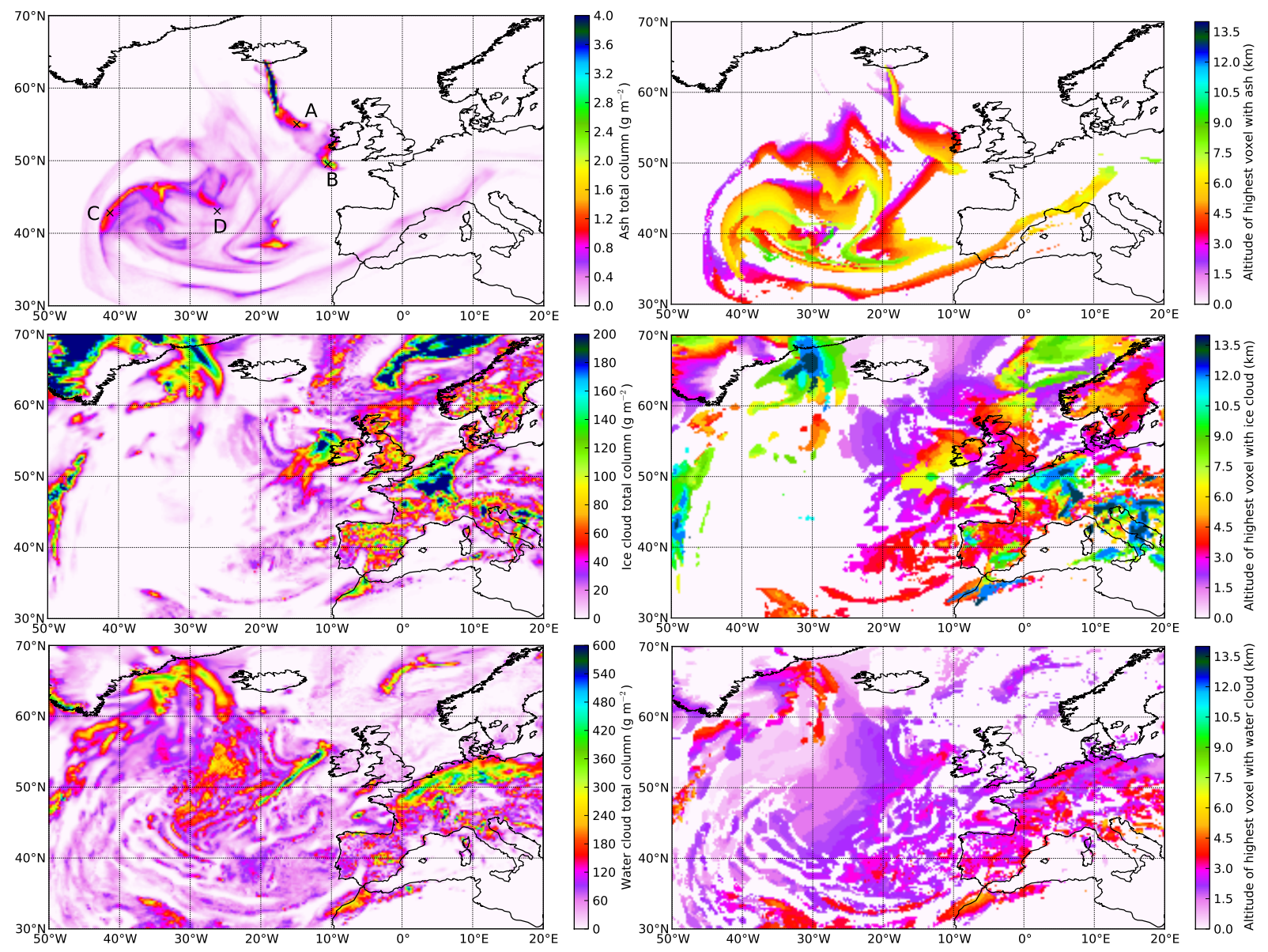

Fig. 5. Left column: the total column density of the ash as simulated by FLEXPART (top panel), ice (middle panel) and water (bottom panel) clouds from ECMWF. Right column: the altitude of the highest voxel with ash concentration above $0.1 \mathrm{mg} \mathrm{m}^{-3}$ (top panel), ice above $10 \mathrm{mg} \mathrm{m}^{-3}$ (middle panel), and water above $50 \mathrm{mg} \mathrm{m}^{-3}$ (bottom panel).

temperature differences (Prata, 1989). The $10.8 \mu \mathrm{m}$ brightness temperature versus the 10.8-12.0 $\mu \mathrm{m}$ BTD is shown in Fig. 6 for both the MYSTIC simulation and the SEVIRI measurement. For the MYSTIC simulation the uppermost cloud type in a pixel is identified by colour by the following method. Whether a voxel contains ash, ice or water clouds is known. Often a voxel contains all three cloud types. For the purpose of labelling, we consider a voxel to contain significant amounts of ash, ice or water if the uppermost cloud densities are larger than $10^{-4}, 0.01$ and $0.05 \mathrm{~g} \mathrm{~m}^{-3}$, respectively. These limits are rather arbitrary chosen so that the map of the uppermost voxel containing ash, ice or water corresponds to 

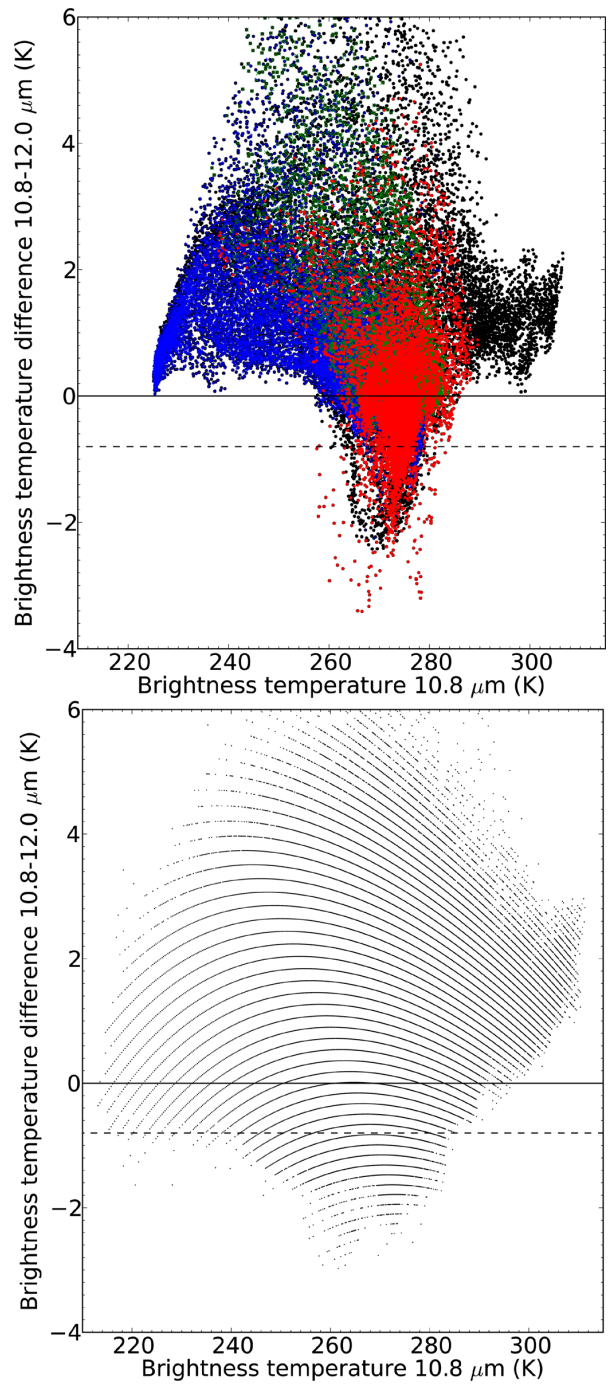

Fig. 6. Top panel: the MYSTIC simulated $10.8 \mu \mathrm{m}$ brightness temperature versus the $10.8-12.0 \mu \mathrm{m}$ brightness temperature difference. Blue, green and red points indicate pixels with ice, water and ash clouds as the uppermost cloud. Black points represents cloudless pixels. The dashed horizontal line indicates the ash limit cut-off. Bottom panel: similar to left panel, but data from SEVIRI. The line structures in the SEVIRI data are due to digitization. The Sahara desert has been excluded from both panels.

the respective maps of the total column (Fig. 5). In Fig. 6 both the simulated and measured BTDs have been corrected for water vapour absorption following Yu et al. (2002). The colour coding shows that most ash pixels do have a negative BTD whereas ice (blue) and liquid (green) water clouds have positive BTDs. The measured $10.8 \mu \mathrm{m}$ BTs have a larger span compared to the modelled $10.8 \mu \mathrm{m}$ BTs (Fig. 6). The ECMWF temperatures are available every $6 \mathrm{~h}$ and may miss some of the variations present in the real atmosphere.

To avoid misidentification of pixels as ash, a conservative cut-off limit on the BTD is used. Here we adopt the value

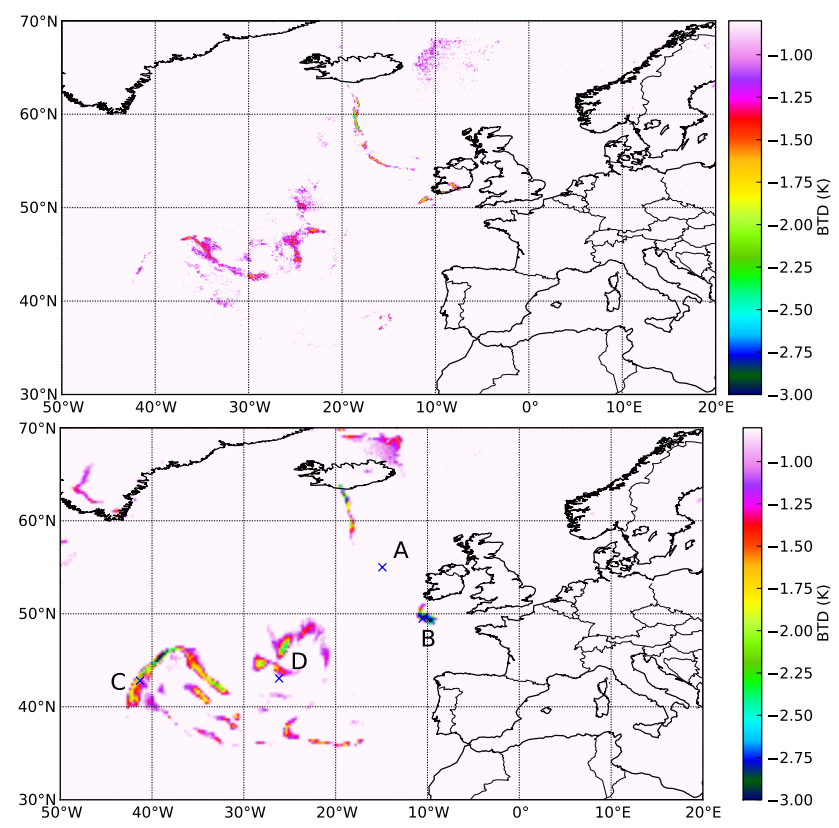

Fig. 7. Pixels identified as ash by the inverse absorption technique. Top panel: the SEVIRI 10.8-12.0 $\mu \mathrm{m}$ channels brightness temperature difference. Bottom panel: the simulated 10.8-12.0 $\mu$ m channels brightness temperature difference.

of $-0.8 \mathrm{~K}$ used by Stohl et al. (2011) and Prata and Prata (2012) for the Eyjafjallajökull eruption. The measured and simulated pixels identified as ash are shown in Fig. 7, top and bottom panels, respectively. Omitting the negative BTDs north and east of Iceland and over Greenland in Fig. 7, it is found that the SEVIRI ash affected pixels cover an area of $481980 \mathrm{~km}^{2}$, while the simulated ash effected pixels cover $479925 \mathrm{~km}^{2}$. Qualitatively the simulation captures the broad features seen in the measurement. Below reasons for differences are discussed.

The near-vent ash is clearly identified in both the measurement and the simulation. At about $55^{\circ} \mathrm{N}$ the measured ash cloud curves eastwards. This part of the ash cloud is not seen in the simulation. The ash cloud input to the radiative transfer model includes the measured eastward curve (top left panel, Fig. 5). The vertical density profiles of the ash, ice and liquid water clouds for the location marked A in the top left panel, Fig. 5, is shown in Fig. 8. The ash, ice and water clouds are mixed up to about $2.75 \mathrm{~km}$ with a thin ash layer on top of the mixed cloud. To be able to detect ash with the reverse absorption method some brightness temperature difference between the ash cloud and the underlying emitting body must be present. In case A this difference is barely present, thus the ash is not seen in the model simulations for location A. As SEVIRI detects ash at location $\mathrm{A}$, the ice and liquid water clouds are slightly misplaced compared to reality, compare also the left and right panels of Fig. 4. The resulting BTD and 

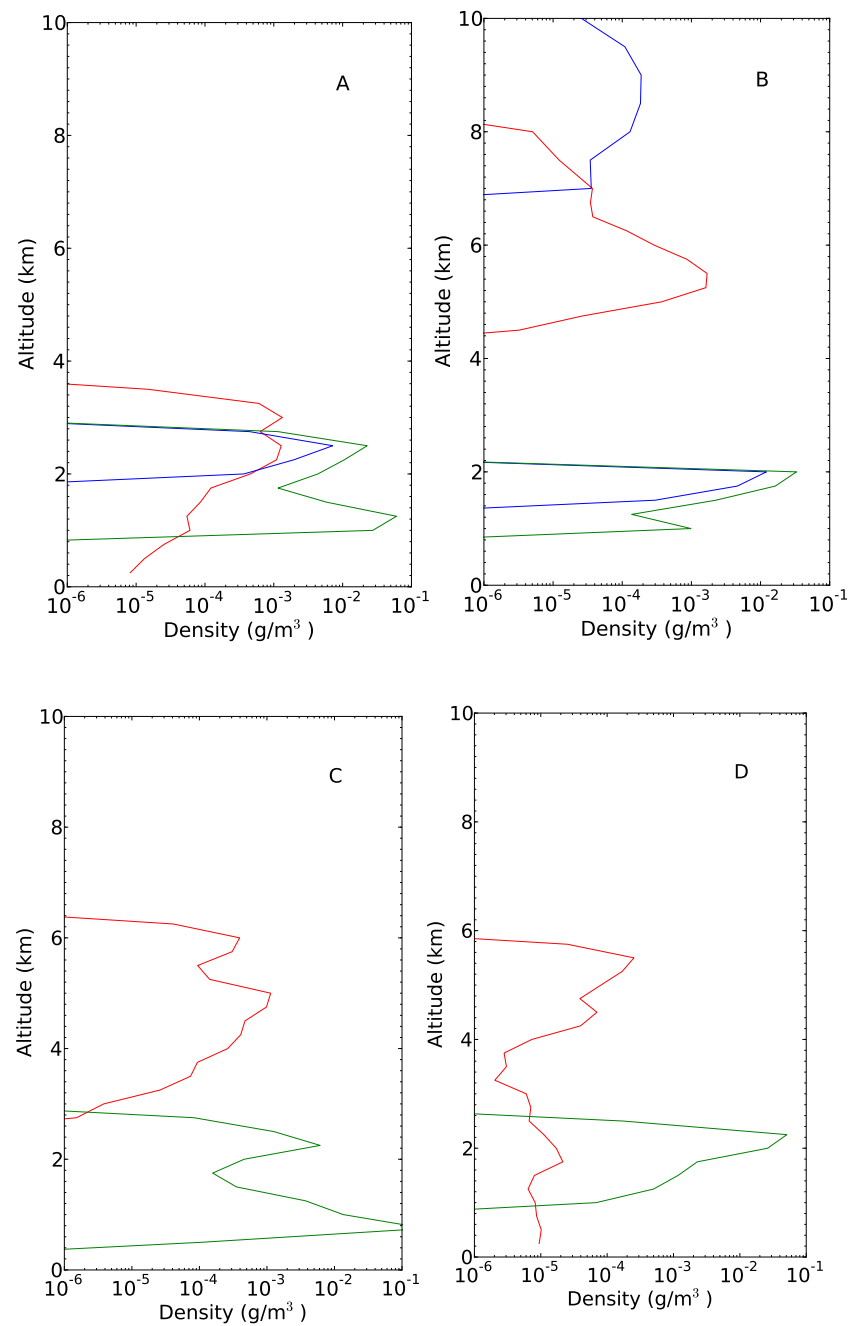

Fig. 8. The vertical ash (red), ice (blue) and water (green) cloud density profiles for the locations A (top left panel), B (top right), C (bottom left panel) and D (bottom right panel) in the top left panel of Fig. 5.

the cloud column densities and cloud top heights are given in Table 1.

The ash patch just southwest of Ireland, location B, appears larger in the simulated than in the measured image. Also, the model result is shifted a little to the south. The ash, ice and water cloud profiles for location B are shown in the second panel of Fig. 8. The ash layer is separated from a low water cloud by a cloudless region. Just above the ash cloud a low density ice cloud is present. The density of the ice clouds is an order of magnitude smaller then that of the ash cloud. The optical depth of the ice cloud increases from 0.10 to 0.12 between 10.8 and $12.0 \mu \mathrm{m}$, whereas the ash cloud optical depth decreases from 0.70 at $10.8 \mu \mathrm{m}$ to 0.91 at $12.0 \mu \mathrm{m}$. The optical depth of the ice cloud is thin enough to permit detection of the ash cloud by the BTD, as is evident from the negative BTD given in Table 1. Removing the ice cloud

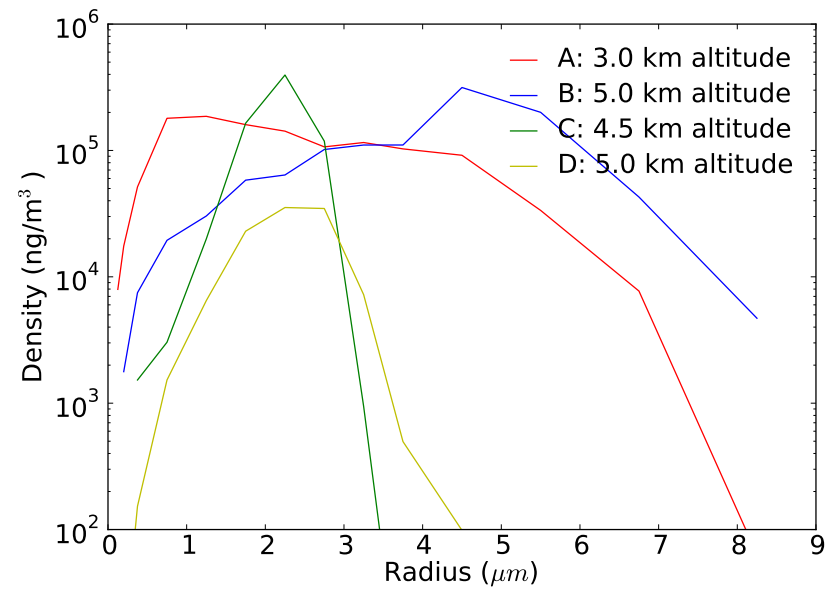

Fig. 9. The ash size distribution for locations A, B, C, and D (see top left panel of Fig. 5 for location). The size distributions are at the altitudes of maximum ash concentrations.

Table 1. The total column densities and altitudes of uppermost layer with ash, ice or water for the four cases in Fig. 8. The modelled 10.8-12.0 $\mu \mathrm{m}$ brightness temperature difference (BTD) for the four cases is given in the last column.

\begin{tabular}{|c|c|c|c|c|c|c|c|}
\hline \multirow[b]{2}{*}{ Case } & \multicolumn{3}{|c|}{$\begin{array}{l}\text { Total column density } \\
\qquad\left(\mathrm{g} \mathrm{m}^{-2}\right)\end{array}$} & \multicolumn{3}{|c|}{$\begin{array}{l}\text { Top height } \\
(\mathrm{km})\end{array}$} & \multirow{2}{*}{$\begin{array}{r}\text { BTD } \\
(\mathrm{K})\end{array}$} \\
\hline & Ash & Ice & Water & Ash & Ice & Water & \\
\hline A & 1.3 & 4.7 & 39.3 & 3.25 & 2.75 & 2.75 & -0.1 \\
\hline B & 2.7 & 2.5 & 18.5 & 8.0 & 10.0 & 2.0 & -3.5 \\
\hline $\mathrm{C}$ & 1.3 & - & 54.2 & 6.5 & - & 2.75 & -1.7 \\
\hline D & 0.2 & - & 33.7 & 5.75 & - & 2.5 & -0.5 \\
\hline
\end{tabular}

decreases the BTD by about $0.1 \mathrm{~K}$, while removing the underlying water cloud decreases the BTD by about $0.5 \mathrm{~K}$.

No ice clouds were present over the Atlantic in the model simulation. Locations C and D are examples of locations where ash is present and detected (C) and not detected (D). The liquid water cloud and ash cloud profiles are shown in the bottom left and right panels of Fig. 8. For location $\mathrm{C}$ the ash cloud is on top of a water cloud and thus readily visible in the simulated data. However, in the measurements the ash cloud is barely detectable. The cause of this discrepancy may be a wrong altitude of the simulated ash cloud or wrong ash load. Furthermore, the ice and water clouds may not be well represented in the model for this region. The MYSTIC and SEVIRI brightness temperatures are different in this region (see Fig. 4), indicating that the cloud structure is more complex than depicted by the ECMWF cloud fields. For location $\mathrm{D}$ the ash is above the water cloud and mixed with the water cloud. However, the larger part of the ash is contained above the water cloud. A slightly negative BTD is calculated from the simulations (Table 1). The value is, however, above the $-0.8 \mathrm{~K}$ cut-off limit. From the profiles and BTDs of locations $\mathrm{A}$ and $\mathrm{D}$ it may be concluded that to obtain sufficiently 


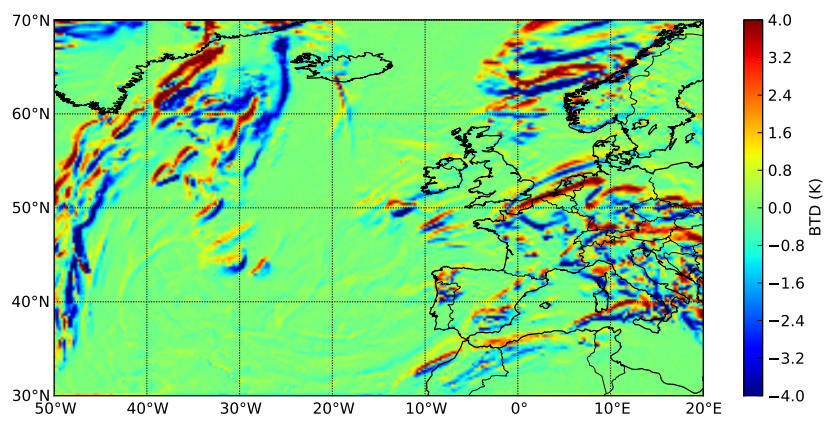

Fig. 10. The $10.8 \mu \mathrm{m}$ brightness temperature difference between a full 3-D simulation and a simulation utilizing the independent pixel approximation.

negative BTDs the ash cloud must be well separated from the underlying water cloud.

The magnitude of the ash signal varies with the amount of ash and with the ash size distribution. For a given size distribution with an effective radius the ash signal increases as the effective radius decreases (Fig. 2, Prata, 1989, Fig. 8, Wen and Rose, 1994, and Fig. 2, Prata and Prata, 2012). For high and low ash mass loadings the BTD is small, thus making identification of ash and retrieval of ash properties difficult. This also implies that a large BTD does not necessarily indicate large amounts of ash. The ash size distribution is determined by the size distribution injected into the atmosphere at the vent, by size-dependent ash removal processes and by ash aggregation. For the four locations discussed above the size distributions are shown in Fig. 9 at the altitudes of maximum ash concentration. Location $\mathrm{A}$ is closest to the vent and has a rather broad size distribution. The size distribution is even broader for location $\mathrm{B}$, indicating that this is ash from the explosive activities on Eyjafjallajökull between 610 May. At locations $C$ and D only the smallest ash particles are still present. Schumann et al. (2011) reports in situ measured effective radii between $0.1-1.4 \mu \mathrm{m}$ depending on mass concentration. It is noted that the radii reported by Schumann et al. (2011) were recorded for a few selected locations and in low ash density regions due to aircraft safety restrictions.

The MYSTIC radiative transfer model allows an individual size distribution to be specified for each voxel. Thus the ash size distribution does not have to be approximated by a simple analytic formula (like the log-normal or gamma distributions) which depends on only one (effective radius) or two (width) parameters. As shown in Fig. 9, the ash size distribution varies considerably over the domain. The adoption of a fixed shaped size distribution with a variable effective radius, may not be representative for the whole domain. To test this the FLEXPART ash field number density $(n(r))$ in Fig. 1 were represented by a gamma distribution, $n(r)=a r^{\alpha} \exp (-b r)$, were $\alpha=6.0$, and $a$ and $b$ are determined from the zeroth and first order moments of the size distribution. Specifically $b=(\alpha+3) / r_{\text {eff }}$, thus the variation
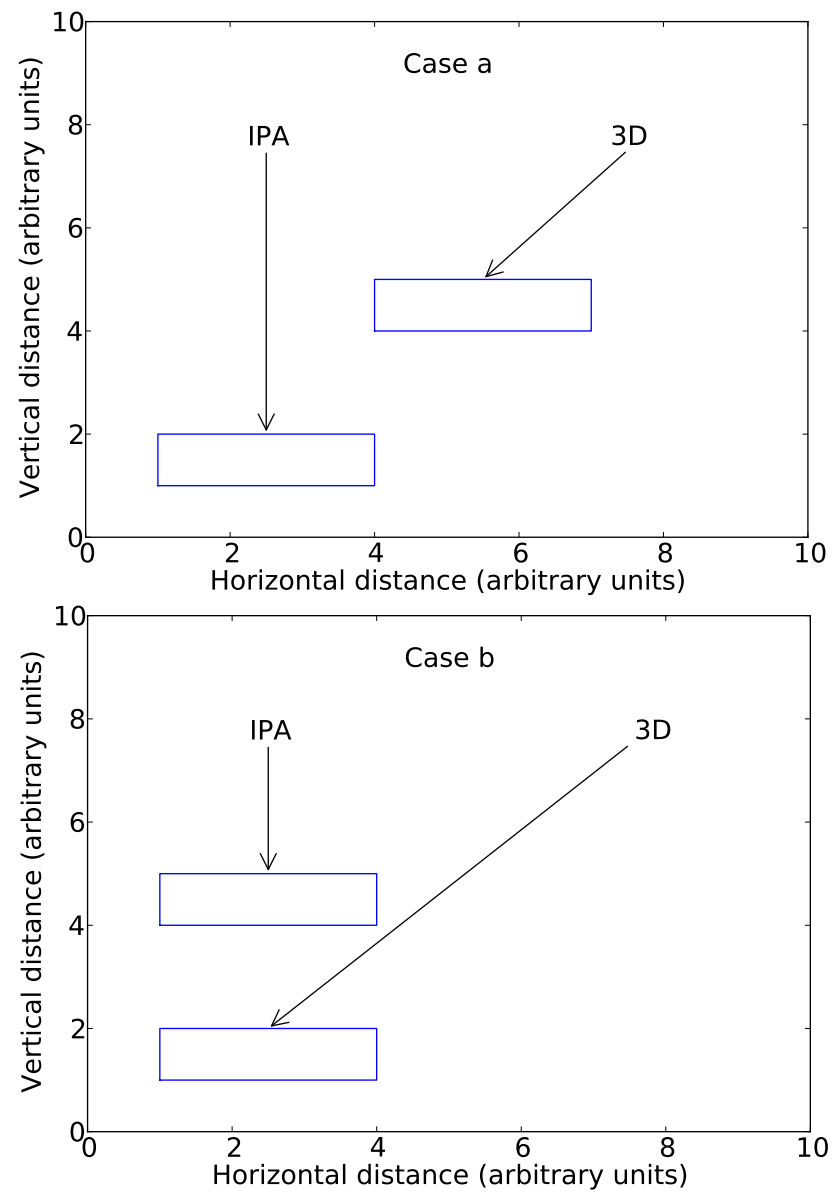

Fig. 11. Clouds "seen" by the IPA approximation and the 3-D simulations for the two different cases described in the text. Arrows indicate the clouds seen.

of the effective radius over the domain was included in the simulations, but not the change in the shape of the size distribution around the effective radius. For the simulations with the ash represented with a gamma distribution (not shown) the near-vent signal seen in Fig. 7 is totally absent. This may have several reasons, including too much ash or too large ash particle radii. The $10.8-12.0 \mu \mathrm{m}$ BTD is more sensitive to changes in the ash particle radius than ash density (Prata, 1989; Wen and Rose, 1994). Thus, the use of a single type size distribution, albeit with varying effective radius, may be inappropriate for the simulations of SEVIRI IR imagery.

\subsection{3-D versus the independent pixel approximation}

A full 3-D radiative transfer model has been used throughout the paper. The independent pixel approximation (IPA) is often used to simulate complex cloud fields. In the IPA each satellite pixel is treated independently, for each pixel the atmosphere is assumed to be horizontally homogeneous and horizontal photon transport is neglected. The IPA ignores interaction with neighbouring pixels, as such it will for 
example miss shadow effects. The limitations of the IPA has been investigated for solar photons by several authors, including Cahalan et al. (1994); Chambers et al. (1997); Marshak et al. (1995); Scheirer and Macke (2001) and Zuidema and Evans (1998). To quote Cahalan et al. (1994): "IPA is accurate only for fluxes averaged over large horizontal areas". IPA simulations may be less demanding on computer resources and the only viable option if no full 3-D radiative transfer solver is available. The effect of the IPA on the present case was investigated by doing an IPA simulation and comparing it with the full 3-D simulation shown in the right panel of Fig. 4. The differences between the 3-D and IPA simulations are shown in Fig. 10. It is noted that differences in the $10.8 \mu \mathrm{m}$ brightness temperature may be as large as $\pm 20-30 \mathrm{~K}$.

The differences between the 3-D and IPA simulations are mainly caused by two effects shown in Fig. 11. In case (a) the two clouds are shifted horizontally. The 3-D simulation "sees" the colder and higher cloud while the IPA "sees" the lower and warmer cloud. In case (b) the two clouds are on top of each other. The 3-D will "see" the lower and warmer cloud from the side, while the IPA sees only the upper cloud. Hence both positive and negative differences are present in Fig. 10. Most of the differences are due to water clouds and careful inspection of Fig. 10 and the cloud top heights in Fig. 5 reveal that the differences coincide with high cloud tops with underlying lower clouds. Differences of IPA versus 3-D are also present close to the vent and south-southwest of Ireland. Satellite images with a large viewing angle imply that the IPA will see colder or warmer temperatures for the same pixel compared with a full 3-D simulation. The demonstrated differences between 3-D and IPA simulations may make quantitative comparisons between IPA simulated brightness temperatures and SEVIRI brightness temperatures difficult. However, as the main difference is caused by parallax effects, this may be corrected with a tilted independent pixel approximation (Varnai and Davies, 1999).

\section{Conclusions}

A new model framework for the simulation of infrared satellite imagery in the presence of volcanic ash clouds has been presented. The model framework includes ash clouds from the FLEXPART Lagrangian particle dispersion model, ice and water clouds from ECMWF analysis and radiative transfer simulations with the 3-D MYSTIC model.

A case from the Eyjafjallajökull eruption has been modelled and analysed using this framework. The simulated case demonstrates that the model framework allows realistic simulation of satellite measurements.

The placement of the ash cloud relative to ice and water clouds obviously has an impact on the ash signal seen by the satellite. For four locations the vertical location of the ash cloud was presented and the effect on the ash signal discussed. Specifically, to be clearly detectable, the ash clouds need to be vertically separated at some distance above other clouds. If ash clouds are mixed with water clouds or are located only slightly above water clouds, detection of the ash becomes difficult. The ash cloud may be detectable through thin ice clouds.

Fully 3-D simulations were performed for the investigated case. In addition, a simulation assuming an independent pixel approximation was performed. For direct comparisons of measured and simulated satellite images, IPA may introduce artifacts due to which part of the sky or ground that effectively is emitting the radiation as simulated by the two approaches.

The new modelling framework can be used for understanding the processes that affect satellite imagery. Furthermore, it constitutes a solid basis for testing existing and new ash retrieval algorithms.

Acknowledgements. ECMWF and met.no are acknowledged for granting access to the ECMWF data used for driving MYSTIC and FLEXPART. EUMETSAT are acknowledged for providing SEVIRI data via EUMETCast. We acknowledge the use of imagery from the Land Atmosphere Near-real time Capability for EOS (LANCE) system operated by the NASA/GSFC/Earth Science Data and Information System (ESDIS) with funding provided by NASA/HQ. Finally, support from the Norwegian Ministry of Transport and Communications is acknowledged. We are grateful to Fred Prata for valuable comments to an early version of the manuscript. Constructive comments from the anonymous referees are greatly appreciated.

Edited by: A. Kokhanovsky

\section{References}

Anderson, G., Clough, S., Kneizys, F., Chetwynd, J., and Shettle, E.: AFGL atmospheric constituent profiles $(0-120 \mathrm{~km})$, Tech. Rep. AFGL-TR-86-0110, Air Force Geophys. Lab., Hanscom Air Force Base, Bedford, Mass., 1986.

Borbas, E. E. and Ruston, B. C.: The RTTOV UWiremis IR land surface emissivity module., NWP SAF report, available at: http://research.metoffice.gov.uk/research/interproj/nwpsaf/ vs_reports/nwpsaf-mo-vs-042.pdf (last access: 11 March 2013), 2010.

Bugliaro, L., Zinner, T., Keil, C., Mayer, B., Hollmann, R., Reuter, M., and Thomas, W.: Validation of cloud property retrievals with simulated satellite radiances: a case study for SEVIRI, Atmos. Chem. Phys., 11, 5603-5624, doi:10.5194/acp-11-5603-2011, 2011.

Buras, R. and Mayer, B.: Efficient unbiased variance reduction techniques for Monte Carlo simulations of radiative transfer in cloudy atmospheres: the solution, J. Quant. Spectrosc. Ra., 112, 434-447, doi:10.1016/j.jqsrt.2010.10.005, 2011.

Buras, R., Dowling, T., and Emde, C.: New secondary-scattering correction in DISORT with increased effiency for forward scattering, J. Quant. Spectrosc. Ra., 112, 2028-2034, doi:10.1016/j.jqsrt.2011.03.019, 2011. 
Cahalan, R. F., Ridgway, W., Wiscombe, W. J., Gollmer, S., and Harshvardhan: Independent pixel and Monte Carlo estimates of stratocumulus albedo, J. Atmos. Sci., 51, 3776-3790, 1994.

Cahalan, R. F., Oreopoulos, L., Marshak, A., Evans, K. F., Davis, A. B., Pincus, R., Yetzer, K. H., Mayer, B., Davies, R., Ackerman, T. P., Barker, H. W., Clothiaux, E. E., Ellingson, R. G., Garay, M. J., Kassianov, E., Kinne, S., Macke, A., O'Hirok, W., Partain, P. T., Prigarin, S. M., Rublev, A. N., Stephens, G. L., Szczap, F., Takara, E. E., Várnai, T., Wen, G., and Zhuravleva, T. B.: The I3RC: bringing together the most advanced radiative transfer tools for cloudy atmospheres, B. Am. Meteorol. Soc., 86, 1275-1293, 2005.

Chambers, L. H., Wielicki, B. A., and Evans, K. F.: Accuracy of the independent pixel approximation for satellite estimates of oceanic boundary layer cloud optical depth, J. Geophys. Res., 102, 1779-1794, 1997.

Eckhardt, S., Prata, A. J., Seibert, P., Stebel, K., and Stohl, A.: Estimation of the vertical profile of sulfur dioxide injection into the atmosphere by a volcanic eruption using satellite column measurements and inverse transport modeling, Atmos. Chem. Phys., 8, 3881-3897, doi:10.5194/acp-8-3881-2008, 2008.

Emde, C., Buras, R., Mayer, B., and Blumthaler, M.: The impact of aerosols on polarized sky radiance: model development, validation, and applications, Atmos. Chem. Phys., 10, 383-396, doi:10.5194/acp-10-383-2010, 2010.

Grant, R. H. and Heisler, G. M.: Multi-waveband solar irradiance on tree-shaded vertical and horizontal surfaces: cloud-free and partly cloudy skies, Photochem. Photobiol., 73, 24-31, 2001.

Gudmundsson, M. T., Thordarson, T., Höskuldsson, Á., Larsen, G., Björnsson, H., Prata, F. J., Oddson, B., Magnússon, E., Högnadóttir, T., Petersen, G. N., Hayward, C. L., Stevenson, J. A., and Jónsdóttir, I.: Ash generation and distribution from the April-May 2010 eruption of Eyjafjallajökull, Iceland, Sci. Rep., 2, 572, doi:10.1038/srep00572, 2012.

Hasager, C. B., Birmili, W., Pappalardo, G., and Prata, F. (Eds.): Atmospheric implications of the volcanic eruptions of Eyjafjallajökull, Iceland 2010, Special Issue, Atmos. Chem. Phys., http://www.atmos-chem-phys.net/special_issue212.html, 2010.

JGR Special Section: The Eyjafjallajökull volcanic eruption 2010, J. Geophys. Res., 116-117, 2011-2012.

Jones, A. R., Thomson, D. J., Hort, M., and Devenish, B.: The UK Met Office's next-generation atmospheric dispersion model, NAME III, Air Pollut. Model. Appl. XVII, 6, 580-589, 2007.

Key, J. R., Yang, P., Baum, B. A., and Nasiri, S. L.: Parameterization of shortwave ice cloud optical properties for various particle habits, J. Geophys. Res., 107, 4181, doi:10.1029/2001JD000742, 2002.

Kristiansen, N. I., Stohl, A., Prata, A. J., Bukowiecki, N., Dacre, H., Eckhardt, S., Henne, S., Hort, M. C., Johnson, B. T., Marenco, F., Neininger, B., Reitebuch, O., Seibert, P., Thomson, D. J., Webster, H. N., and Weinzierl, B.: Performance assessment of volcanic ash transport model mini-ensemble used for inverse modeling of the 2010 Eyjafjallajökull eruption, J. Geophys. Res., 117, D00U11, doi:10.1029/2011JD016844, 2012.

Marshak, A., Davis, A., Wiscombe, W., and Titov, G.: The versimilitude of the independent pixel approximation used in cloud remote sensing, Remote Sens. Environ., 52, 71-78, 1995.

Martin, G. M., Johnson, D. W., and Spice, A.: The measurement and parameterization of effective radius of droplets in warm stra- tocumulus clouds, J. Atmos. Sci., 51, 1823-1842, 1994.

Mayer, B.: Radiative transfer in the cloudy atmosphere, Eur. Phys. J. Conf., 1, 75-99, 2009.

Mayer, B. and Kylling, A.: Technical note: The libRadtran software package for radiative transfer calculations - description and examples of use, Atmos. Chem. Phys., 5, 1855-1877, doi:10.5194/acp-5-1855-2005, 2005.

Mayer, B., Hoch, S. W., and Whiteman, C. D.: Validating the MYSTIC three-dimensional radiative transfer model with observations from the complex topography of Arizona's Meteor Crater, Atmos. Chem. Phys., 10, 8685-8696, doi:10.5194/acp-10-86852010, 2010.

McFarquhar, G. M., Iacobellis, S., and Somerville, R. C. J.:SCM simulations of tropical ice clouds using observationally based parameterizations of microphysics, J. Climate, 16, 1643-1664, 2003.

Millington, S. C., Saunders, R. W., Francis, P. N., and Webster, H. N.: Simulated volcanic ash imagery: a method to compare NAME ash concentration forecasts with SEVIRI imagery for the Eyjafjallajökull eruption in 2010, J. Geophys. Res., 117, D00U17, doi:10.1029/2011JD016770, 2012.

Pierluissi, J. H. and Peng, G.-S.: New molecular transmission band models for LOWTRAN, Opt. Eng., 24, 541-547, 1985.

Pollack, J. B., Toon, O. B., and Khare, B. N.: Optical properties of some terrestrial rocks and glasses, Icarus, 19, 372-389, 1973.

Prata, A. J.: Infrared radiative transfer calculations for volcanic ash clouds, Geophys. Res. Lett., 16, 1293-1296, 1989.

Prata, A. J. and Grant, I. F.: Retrieval of microphysical and morphological properties of volcanic ash plumes from satellite data: application to Mt Ruapehu, New Zealand, Q. J. Roy. Meteorol. Soc., 127, 2153-2179, 2001.

Prata, A. J. and Prata, A. T.: Eyjafjallajökull volcanic ash concentrations determined using spin enhanced visible and infrared imager measurements, J. Geophys. Res., 117, D00U23, doi:10.1029/2011JD016800, 2012.

Ricchiazzi, P., Yang, S., Gautier, C., and Sowle, D.: SBDART: a research and teaching software tool for plane-parallel radiative transfer in the Earth's atmosphere, B. Am. Meteorol. Soc., 79, 2101-2114, 1998.

Saunders, R. W., Matricardi, M., and Brunel, P.: An improved fast radiative transfer model for assimilation of satellite radiance observations, Q. J. Roy. Meteorol. Soc., 125, 1407-1425, 1999.

Scheirer, R. and Macke, A.: On the accuracy of the independent column approximation in calculating the downward fluxes in the UVA, UVB, and PAR spectral ranges, J. Geophys. Res., 106, 14301-14312, 2001.

Schumann, U., Weinzierl, B., Reitebuch, O., Schlager, H., Minikin, A., Forster, C., Baumann, R., Sailer, T., Graf, K., Mannstein, H., Voigt, C., Rahm, S., Simmet, R., Scheibe, M., Lichtenstern, M., Stock, P., Rüba, H., Schäuble, D., Tafferner, A., Rautenhaus, M., Gerz, T., Ziereis, H., Krautstrunk, M., Mallaun, C., Gayet, J.F., Lieke, K., Kandler, K., Ebert, M., Weinbruch, S., Stohl, A., Gasteiger, J., Groß, S., Freudenthaler, V., Wiegner, M., Ansmann, A., Tesche, M., Olafsson, H., and Sturm, K.: Airborne observations of the Eyjafjalla volcano ash cloud over Europe during air space closure in April and May 2010, Atmos. Chem. Phys., 11, 2245-2279, doi:10.5194/acp-11-2245-2011, 2011.

Stamnes, K., Tsay, S.-C., Wiscombe, W., and Jayaweera, K.: Numerically stable algorithm for discrete-ordinate-method radia- 
tive transfer in multiple scattering and emitting layered media, Appl. Optics, 27, 2502-2509, 1988.

Stohl, A., Hittenberger, M., and Wotawa, G.: Validation of the Lagrangian particle dispersion model FLEXPART against large scale tracer experiment data, Atmos. Environ., 32, 4245-4264, 1998.

Stohl, A., Forster, C., Frank, A., Seibert, P., and Wotawa, G.: Technical note: The Lagrangian particle dispersion model FLEXPART version 6.2, Atmos. Chem. Phys., 5, 2461-2474, doi:10.5194/acp-5-2461-2005, 2005.

Stohl, A., Prata, A. J., Eckhardt, S., Clarisse, L., Durant, A., Henne, S., Kristiansen, N. I., Minikin, A., Schumann, U., Seibert, P., Stebel, K., Thomas, H. E., Thorsteinsson, T., Tørseth, K., and Weinzierl, B.: Determination of time- and height-resolved volcanic ash emissions and their use for quantitative ash dispersion modeling: the 2010 Eyjafjallajökull eruption, Atmos. Chem. Phys., 11, 4333-4351, doi:10.5194/acp-11-4333-2011, 2011.

Thomas, H. E. and Prata, A. J.: Sulphur dioxide as a volcanic ash proxy during the April-May 2010 eruption of Eyjafjallajökull Volcano, Iceland, Atmos. Chem. Phys., 11, 6871-6880, doi:10.5194/acp-11-6871-2011, 2011.
Varnai, T. and Davies, R.: Effects of cloud heterogeneities on shortwave radiation: comparison of cloud-top variability and internal heterogeneity, J. Atmos. Sci., 56, 4206-4224, 1999.

Wen, S. and Rose, W. I.: Retrieval of sizes and total masses of particles in volcanic clouds using AVHRR bands 4 and 5, J. Geophys. Res., 99, 5421-5431, 1994.

Wyser, K.: The effective radius in ice clouds, J. Climate, 11, 1793 $1802,1998$.

Yang, P., Wei, H., Huang, H.-L., Baum, B. A., Hu, Y. X., Kattawar, G. W., Mishchenko, M. I., and Fu, Q.: Scattering and absorption property database for nonspherical ice particles in the near- through far-infrared spectral region, Appl. Optics, 44, 5512-5523, 2005

Yu, T., Rose, W. I., and Prata, A. J.: Atmospheric correction for satellite-based volcanic ash mapping and retrievals using "split window" IR data from GOES and AVHRR, J. Geophys. Res., 107, 4311, doi:10.1029/2001JD000706, 2002.

Zuidema, P. and Evans, K. F.: On the validity of the independent pixel approximation for boundary layer clouds observed during ASTEX, J. Geophys. Res., 103, 6059-6074, 1998. 